\title{
On the carbon cycle and its interactions with the biosphere
}

\author{
Nabil H. Swedan ${ }^{1}$ \\ Received 31 October 2018; accepted 21 November 2018; published 10 April 2019.
}

The submitted work reveals that interactions between the carbon cycle and the biosphere may be calculated using traditional thermodynamic equations. Presently, anthropogenic activities have changed the natural carbon cycle and climate parameters, which have direct effects at the societal and economical levels. For instance, engineering design parameters particularly those related to civil, environmental, and agricultural projects will not be the same as today. They will be different as long as the interactions between humans and the environment continue their present trends. The thermodynamic analysis of these interactions is broad and complex, and the manuscript is limited to providing parameterizations of the analysis. The observed surface warming is caused by heat produced by the carbon cycle. Deforestation has averaged nearly $0.19 \%$ annually since the Industrial Revolution, and its present contribution to surface warming is about $50 \%$. The remainder of surface warming is attributed to energy produced by the world, which has a decreasing trend of $-0.82 \%$ annually. The contribution of deforestation to surface warming has a decreasing trend as well, and the net surface greening is increasing by $0.08 \%$ annually. Approximate current precipitation trend is $-0.31 \mathrm{~mm}$ annually, which is considerably greater than that of past natural climates. KEYWORDS: Carbon cycle; climate change; thermodynamics; energy production; deforestation; surface greening.

Citation: Swedan, Nabil H. (2019), On the carbon cycle and its interactions with the biosphere, Russ. J. Earth. Sci., 19, ES2007, doi:10.2205/2018ES000643.

\section{Introduction}

The carbon cycle involves living matter and inert environment that appear to interact in accordance with the natural laws of thermodynamics. The green matter belongs to the first level of the food chain, and non-green living matter depends on the green matter. Variation in the mass of life in the biosphere thus can be estimated by knowing variation in the content of carbon dioxide in the

\footnotetext{
${ }^{1}$ Pacific Engineering PLLC, Olympia, Washington, USA
}

Copyright 2019 by the Geophysical Center RAS. http://rjes.wdcb.ru/doi/2018ES000643-res.html atmosphere. Green plants and vegetation convert carbon dioxide and water by photosynthesis into glucose, cellulose, sugars, carbohydrates and other vegetation basic constituents. Solar energy is required for photosynthesis, and this process can be thought of as energy and carbon sink in the carbon cycle, stored in the biosphere as chemical energy. When the size of life expands, more of the solar energy is converted into chemical energy, and the surroundings receive less solar heat. The temperature of the surface decreases. Conversely, plants decay, oxidation, or combustion produce heat of carbon conversion to carbon dioxide that raises surface temperature. Variation in the size of life thus could have caused past warming and cooling cycles of the surface. Given that the earth must have 
reached equilibrium by now, climate change thermodynamic transformations may be considered infinitesimal displacements from equilibrium. The equations of thermodynamic equilibrium may thus be extended to the carbon cycle and traditional thermodynamics used to analyze the interactions between the carbon cycle and biosphere subsystems.

Since human invention of farming, the environmental change has disabled the natural carbon cycle. Energy production adds heat and carbon dioxide to the environment, and these should be accounted for in the thermodynamic analysis. Deforestation removes heat sink from the surface, and in turn, solar heat that otherwise would have been stored as chemical energy, warms the surface. These human related activities may be assessed using proven thermodynamic relationships that have passed the test of time.

In this paper, thermodynamic equations related to interactions between biosphere subsystems are derived, and the significance of the derived equations is then discussed. Sample calculations are provided so that the calculations may be reproduced by others. The paper discusses results of the calculations, alignment with observation, and potential use of the work for practical applications.

\section{Background Information}

Plants growth follows Liebig's law, or the law of the minimum. The law states that plants growth is controlled not by the resources available, but by the scarcest resource, or limiting factor. For the green matter on the surface, water and carbon dioxide are resources for photosynthesis, and their concentrations are variable with the climate. Consequently, variation in the size of the green matter may be assessed by knowing carbon dioxide, evaporation, and precipitation trends. These are climate related parameters, and, therefore, present climate science understanding and limitations are discussed first. Parameterizations of the thermodynamics of the carbon cycle is then introduced.

[Petit et al., 1999 reveals a correlation between carbon dioxide content in the atmosphere and surface temperature of past climates. If the content of carbon dioxide in the atmosphere increases, surface temperature increases and vice versa. This publi- cation attributes past climate changes to variation in carbon dioxide and Milankovitch cycles. The relevant cycle has a periodicity of $1.00 \times 10^{5}$ years, and varies the value of the solar constant with time. Because the present warming trend is three hundred years or less, Milankovitch cycles can be excluded as a cause of the ongoing climate change.

The current climate understanding attributes surface warming to anthropogenic climate agents whose net result is solar heat being trapped in the climate system. Carbon dioxide emission is the major anthropogenic cause. The Intergovernmental Panel on Climate Change (IPCC) summarizes present climate understanding in reports, the latest of which is $[I P C C, 2013$. Chapter 8 of this report is dedicated to climate drivers through the Radiative Forcing (RF) concept. The Chapter provides literature for further reading on present-day climate science. $\mathrm{RF}$ is the net change in the energy balance due to imposed perturbations. $\mathrm{RF}$ measures variations in the net radiative flux at the top of the atmosphere, and climate change occurs due to variations in RF. A relationship between RF and equilibrium global mean surface temperature, $\Delta T$, is derived, $\mathrm{RF}=\lambda \Delta T$. Where $\lambda$ is climate sensitivity (in $\mathrm{W} \mathrm{m}^{-2}{ }^{\circ} \mathrm{K}^{-1}$ ), whose value is yet to be determined with certainty. Derivation of this equation is based on differential displacement of the climate from radiative equilibrium.

Modern climate models are typically used for investigating the response of climate to various climate agents. Chapter 9 of $[I P C C, 2013$ is dedicated to evaluation and application of climate models and includes literature for further reading on the subject. An over review of model type is presented under Section 9.1.2, and a partial list includes: Atmosphere-Ocean General Circulation Model, Earth System models, Earth System Model of Intermediate Complexity, and Regional Climate Models. The carbon cycle and other biosphere components appear to be added as new components to some Earth System Models of climate, [IPCC, 2013 Chapter 9, Section 9.1.3.1.3, Section 9.4.5, Tables 9.A.1 and 9.A.2; Chapter 12, Section 12.4.8, Section 12.4.8.2. Climate models appear to provide no calculated values of deforestation and surface greening, required biosphere components for this work in order to assess variation in the size of the green matter.

This work reveals that causes of climate variability are internal, within the climate system. They 
are not externally forced by the sun. Specifically, interactions of the carbon cycle with the biosphere caused past variations in climates. Milankovitch cycles are weak and could not have caused global changes of past climates. The most severe scenario is when orbital eccentricity varies between 0.05 and 0.005 . Variation in the annual average value of the solar constant is nearly $4.5 \%$ at the most. This variation is less than its present seasonal variation of approximately $7.5 \%$. At the global level, the maximum solar contribution to past cooling and warming cycles must, therefore, be less than one degree ${ }^{\circ} \mathrm{K}$ based on observations (NOAA, National Oceanic and Atmospheric Administration, National Climate Data Center, Global Surface Temperature Anomalies, Mean Monthly Surface Temperature Estimates for the Base Period 1901 to 2000, https://www.ncdc.noaa.gov/monitoring-refe rences/faq/anomalies.php). This is too small compared with the observed past climate surface temperature variations of $10^{\circ} \mathrm{K}$ to $12^{\circ} \mathrm{K}$.

The work presented in this manuscript indicates that heat produced by the carbon cycle warms the surface, and heat removed by the carbon cycle cools the surface. They can be calculated with accuracy because they are correlated with variation in the content of carbon dioxide in the atmosphere and the atmosphere behaves as an ideal gas. In addition, climate change may be considered as a thermodynamic transformation displaced differentially from equilibrium, which simplifies the calculations. Surface temperature rise is less than one degree ${ }^{\circ} \mathrm{K}$ since the Industrial Revolution, assumed by IPCC as 1750 . If compared with surface temperature of $288^{\circ} \mathrm{K}$, the entire climate change is in fact a differential displacement from equilibrium. On annual basis, the observed climate change is an infinitesimal process. Because the earth must have reached equilibrium prior to the Industrial Revolution, climate change may be assumed as a thermodynamic process, or a series of them, displaced differentially from equilibrium.

[Perry and Green, 1984] summarize the current understanding of thermodynamics, whose laws are primitive and basic laws of nature. It is an established branch of science that addresses transformations involving energy exchange between thermodynamic systems and their surroundings. "A thermodynamic system is set apart mentally from everything else, which is called the surroundings. The imaginary envelope that separates the system from its surroundings is the boundary of the system. A closed thermodynamic system exchanges with its surroundings energy and matter is not exchanged. The mass of the system remains unchanged. An open system on the other hand exchanges matter and energy with its surroundings. For open system, the mass and concentration of its species are variable. When a system at a state of thermodynamic equilibrium receives heat, it undergoes a spontaneous thermodynamic process, and its thermodynamic properties vary until a new equilibrium state is reached. During the thermodynamic process, heat and work are exchanged between system and surroundings." At equilibrium the total entropy of system and surroundings approaches maximum and Gibbs Function approaches minimum value.

The earth as a whole may be considered to exchange negligible matter with outer space. It is thus a closed thermodynamic system that has been absorbing solar heat for a long time. This is a spontaneous thermodynamic process and thermodynamic equilibrium must have been reached long time ago. Neglecting variation in the entropy of outer space based on the third law of thermodynamics, then the entropy of the earth is at a maximum and Gibbs Function is at a minimum. They vary with the motion of the earth around the sun, but the variation is infinitesimal, given that the maximum variation in the solar constant is $3.8 \%$ in nearly six month. Likewise, climate change is infinitesimal displacement from equilibrium as discussed earlier. It is thus reasonable to use the equations of thermodynamic equilibrium to analyze the climate.

Unlike laboratory experiments or practical applications, the earth's subsystems are large in size, and the temperature, pressure, and concentration of their species are not always uniform. It is, however, practical to assume that the atmosphere is well mixed and the concentrations of atmospheric species are uniform. This fundamental requirement for thermodynamic analysis is satisfied. The average temperature of the atmosphere may be used, and the external pressure to which the atmosphere is subjected may be neglected. The reason is that, the atmospheric air expands and contracts in a surrounding outer space whose pressure is negligible. Any spherical finite element of the atmosphere has a constant pressure that is equal to the mass of the 
air above it. These considerations are important for thermodynamic analysis of the carbon cycle.

\section{Thermodynamics}

Based on [Perry and Green, 1984], the thermodynamic relationships for open or closed thermodynamic systems with composition change regardless of the cause follow

$$
\begin{gathered}
d(n G)=-(n S) d T+(n V) d P+\Sigma \mu_{i} d n_{i} \\
\mu_{i}=\left[\partial(n H) / \partial n_{i}\right]_{n S, P, n_{j}} \\
{[\partial(n G) / \partial T]_{P}=-n S}
\end{gathered}
$$

where $G$ - molar Gibbs Function of the thermodynamic system, $\mathrm{J} \mathrm{mol}^{-1}$;

$S$ - molar entropy of the thermodynamic system, $\mathrm{J} \mathrm{mol}^{-1}{ }^{\circ} \mathrm{K}^{-1}$;

$n$ - total number of moles in the system;

$n_{i}$ - total number of moles of the chemical specie, $i$, present in the system;

$n_{j}$ - number of moles of all species other than specie, $i$, to be held as constant;

$T$ temperature of the thermodynamic system, ${ }^{\circ} \mathrm{K}$;

$V$ - molar volume of the thermodynamic system, $\mathrm{m}^{3} \mathrm{~mol}^{-1}$;

$P$ - pressure of the thermodynamic system, Pa; $\mu_{i}$ - chemical potential of the i-th specie, $\mathrm{J} \mathrm{mol}^{-1}$; $H$ - molar enthalpy of the thermodynamic system, $\mathrm{J} \mathrm{mol}^{-1}$.

The carbon cycle process equations in the biosphere and surrounding air follow

$$
\begin{aligned}
& \mathrm{C}+\mathrm{O}_{2} \Rightarrow \mathrm{CO}_{2}, \quad \Delta \mathrm{H}_{c}=-393.14 \\
& \text { (0) (0) (-393.14) } \\
& \underset{(-285.57)}{\mathrm{H}_{2} \mathrm{O}(v)} \Rightarrow \underset{(-241.60)}{\mathrm{H}_{2} \mathrm{O}(l),} \quad \Delta H_{v}=43.97 \\
& 6 \mathrm{CO}_{2}(g)+6 \mathrm{H}_{2} \mathrm{O}(l) \stackrel{\text { Light/Chlorophyll }}{\Rightarrow} \\
& (-393.14) \quad(-241.60) \\
& \Rightarrow \mathrm{C}_{6} \mathrm{H}_{12} \mathrm{O}_{6}(s)+6 \mathrm{O}_{2}(g) \\
& (-985)
\end{aligned}
$$

$$
\Delta \mathrm{H}_{c, G}=-2826.0
$$

Equation (4) occurs spontaneously and produces heat of carbon combustion, oxidation, and decay of the green matter in the climate system. Equation (6) on the other hand is non-spontaneous and requires solar energy to produce glucose, which is the basis for plants and vegetation constituents. This photosynthesis process removes solar heat from the climate system and stores it as chemical energy. The values in parenthesis are standard enthalpies of formation and $\Delta H_{c}$ and $\Delta H_{v}$ are the calculated enthalpies of combustion and water evaporation respectively, all in $\mathrm{KJ} \mathrm{mol}^{-1}$. Equation (5) is presented for the scenario where water vapor condenses from the atmosphere. This applies to past interglacial periods and the current warming trend.

\section{Atmosphere}

The atmospheric air is reasonably mixed and homogenous, and the equations of equilibrium may be used for states differentially displaced from equilibrium. In the proximity of equilibrium, system entropy is displaced differentially from its equilibrium value and may be assumed as a constant. As discussed in the background section, the pressure of the atmosphere is constant. Therefore, the partial differential of equation (2) at constant pressure and entropy conditions may be eliminated

$$
\mu_{i}=\frac{d(n H)}{d n_{i}}
$$

Equation (7) reveals that for the specie, $i$, the chemical potential is closely equal to variation in the enthalpy of the system per one mole of this specie. For carbon dioxide and water vapor, the chemical potential is thus equal to $\Delta H_{c}$ and $\Delta H_{v}$ respectively.

Theoretically, the atmosphere is an open thermodynamic system and exchanges water vapor and carbon dioxide with the surface. In practice, variation of these species is so small compared with the mass of the atmosphere and this mass may be assumed as a constant, a closed thermodynamic system. In the proximity of equilibrium, $d(n G)=0$, and for a constant atmospheric pressure, equation (3) yields $[\partial(n G) / \partial T]_{P}=d(n G) / d T=-n S$. Equation (1) for the atmosphere having water vapor and carbon dioxide as variable chemical species gives 


$$
\mu_{\mathrm{H}_{2} \mathrm{O}} d n_{\mathrm{H}_{2} \mathrm{O}}=-\mu_{\mathrm{CO}_{2}} d n_{\mathrm{CO}_{2}}
$$

Substituting the values of $\mu_{\mathrm{H}_{2} \mathrm{O}}$ and $\mu_{\mathrm{CO}_{2}}$ with $\Delta H_{v}$ and $\Delta H_{c}$ respectively

$$
\begin{gathered}
d n_{\mathrm{H}_{2} \mathrm{O}}=-\left(\Delta H_{c} / \Delta H_{v}\right) d n_{\mathrm{CO}_{2}}= \\
(393.14 / 43.97) d n_{\mathrm{CO}_{2}}=8.94 d n_{\mathrm{CO}_{2}}
\end{gathered}
$$

\section{Surface of the Earth}

Referring to equation (6), photosynthesis is shown to produce glucose. In reality, the process is complex, and the products include but not limited to carbohydrates, sugars, cellulous, and others. Regardless of the nature of photosynthesis products, this process is a heat sink at the surface of the earth in that solar energy is converted into chemical energy by the green matter and the surroundings receive less solar heat. Carbon combustion on the other hand, equation (4), is a heat supply in the carbon cycle. All of the heat produced by carbon conversion to carbon dioxide is returned to the surface as latent heat of water vapor condensation, equation (9). For infinitesimal climate change process, the energy balance of the surface of the earth follows

$$
d Q_{S}=d n_{\mathrm{H}_{2} \mathrm{O}} \Delta H_{v}+\Delta H_{c, G} d n_{G}
$$

where $Q_{S}$ is surface heat and $\Delta H_{c, G}$ and $d n_{G}$ are the heat of combustion and variation in the number of moles of the green matter respectively, assumed as glucose. Not considered in the energy balance of the surface, equation (10), radiation terms or internal heat produced in the earth's core. This is a climate energy balance in the proximity of an equilibrium state. Non-carbon producing sources of energy cannot be part of equation (8) or the energy balance, equation (10), and have to exit the climate system. Thermodynamics of the carbon cycle does alter radiation rates of the earth subsystems. However, if the outgoing radiation decreases, the incoming radiation must decrease equally and vice versa to maintain near equilibrium thermodynamic state.

\section{Significance of the Derived Equations}

Equation (9) reveals that an increase in the content of carbon dioxide in the atmosphere increases the amount of water vapor in the atmosphere. This implies a decrease in water vapor condensation and precipitation. To maintain the atmosphere near equilibrium conditions, water vapor must condense onto the surface. The latent heat of water vapor condensation warms the surface. The opposite is the case if the content of carbon dioxide decreases with time, and for this case, more water vapor must condense in the atmosphere instead of the surface. Surface evaporation increases and surface temperature decreases.

To calculate present precipitation reduction, a curve fit of carbon dioxide trend with time may be prepared and equation (9) integrated. Alternatively, the curve may be divided into smaller and linear segments and precipitation trend calculated using a simple mathematical equation, which can be derived: For a series of climate thermodynamic processes covering, $n$, years, equation (9) yields

$$
\Delta \Gamma=-\Delta n_{\mathrm{H}_{2} \mathrm{O}}=-\sum_{0}^{n}{ }_{i} 8.94 d\left(n_{\mathrm{CO}_{2}}\right)_{i}
$$

where $\Delta \Gamma$ is the total variation in precipitation in, $n$, years, which is equal to the opposite sign of $\left(\Delta n_{\mathrm{H}_{2} \mathrm{O}}\right)$ and $d\left(n_{\mathrm{CO}_{2}}\right)_{i}$ is variation in the concentration of carbon dioxide in the atmosphere for the $i$-th year. The concentration of carbon dioxide is typically provided at the end of the year. Assuming the total change in the number of moles of carbon dioxide at the conclusion of the $n$-th year is $\Delta n_{\mathrm{CO}_{2}}$, linearity yields $d\left(n_{\mathrm{CO}_{2}}\right)_{i}=(i / n) \Delta n_{\mathrm{CO}_{2}}$. Equation (11) gives

$$
\begin{gathered}
\Delta \Gamma=-(1 / n) \times 8.94 \times \Delta n_{\mathrm{CO}_{2}} \sum_{0}^{n}{ }_{i} i= \\
-(1 / n) 8.94 \times \Delta n_{\mathrm{CO}_{2}}(0+n) \times n / 2 \\
\Delta \Gamma=-4.47 \times n \times \Delta n_{\mathrm{CO}_{2}}
\end{gathered}
$$

The content of carbon dioxide in the atmosphere is typically reported in parts per million by volume, ppmv. The mass of the atmosphere is $5.18 \times 10^{18} \mathrm{~kg}$ 
[Fleagle and Businger, 1980] and the molecular weight of the atmosphere is 28.8. Equation (12) in ppmv carbon dioxide follows

$$
\Delta \Gamma=-8.04 \times 10^{14} \times n \times \Delta \operatorname{ppmv}_{\mathrm{CO}_{2}}
$$

where $\Delta \operatorname{ppmv}_{\mathrm{CO}_{2}}$ is the total variation in the concentration of carbon dioxide measured in ppmv at the conclusion of the $n$-th year.

Referring to equations $(9)$ and $(10)$, the first term on the right-hand side of equation (10) changes sign with carbon dioxide trend in the atmosphere. If carbon dioxide in the atmosphere has a decreasing trend, the term is negative and heat is removed from the surface. If, however, the trend of carbon dioxide is positive, heat is added to the surface. The second term, $\Delta H_{c, G} d n_{G}$, varies sign with the size, or surface cover, of the green matter. If the area covered by plants and vegetation increases, less solar energy is received by the surroundings and the term is negative. Conversely, if the size of the green matter decreases, more solar heat is added to the surroundings and the term is positive. Both of the terms can be calculated theoretically by knowing trends of carbon dioxide in the atmosphere, and the total energy exchanged with surface computed. For more clarity, equation 10 will be simplified

$$
\begin{gathered}
d Q_{s}=d Q_{c}+d Q_{g} \\
d Q_{c}=d n_{\mathrm{H}_{2} \mathrm{O}} \Delta H_{v}=-\Delta H_{c} d n_{\mathrm{CO}_{2}}= \\
393.14 \times 10^{3} d n_{\mathrm{CO}_{2}} \\
d Q_{g}=\Delta H_{c, G} d n_{G}
\end{gathered}
$$

where $Q_{s}$ - energy of the surface, $\mathrm{J} ; Q_{c}$ - energy produced by carbon conversion to carbon dioxide, $\mathrm{J} ; Q_{g}$ - energy produced by the green matter, J.

Similarly, for linear trend, the procedure used between equation (11) through $(13)$ can be repeated and equation (15) yields

$$
\Delta Q_{c}=3.54 \times 10^{19} \times n \times \Delta \mathrm{ppmv}_{\mathrm{CO}_{2}}
$$

where $\Delta Q_{C}$ is variation in the heat of carbon conversion to carbon dioxide in, $n$, years. Greening of the surface may be estimated from kinetics of the chemical reaction of equation (6)

$$
K_{e}=\left[\mathrm{C}_{6} \mathrm{H}_{12} \mathrm{O}_{6}\right]\left[\mathrm{O}_{2}\right]^{6} /\left[\mathrm{H}_{2} \mathrm{O}\right]^{6}\left[\mathrm{CO}_{2}\right]^{6}
$$

where $K_{e}$ is the constant of equilibrium of photosynthesis and the brackets indicate concentration of products and reactants of the chemical reaction. Given that water and glucose are virtually in pure liquid and solid phases, their concentrations may be assumed to be equal to unity. For two consecutive thermodynamic processes having states of equilibrium, a, and, b, respectively displaced differentially from each other, the constant of equilibrium may be assumed to be the same. Equation (17), applied twice for states, a, and, b, yields

$$
\begin{gathered}
{\left[\mathrm{O}_{2}\right]_{a}^{6} /\left[\mathrm{O}_{2}\right]_{b}^{6}=\left[\mathrm{CO}_{2}\right]_{a}^{6} /\left[\mathrm{CO}_{2}\right]_{b}^{6}} \\
\left(\left[\mathrm{O}_{2}\right]_{a}-\left[\mathrm{O}_{2}\right]_{b}\right) /\left[\mathrm{O}_{2}\right]_{b}= \\
\left(\left[\mathrm{CO}_{2}\right]_{a}-\left[\mathrm{CO}_{2}\right]_{b}\right) /\left[\mathrm{CO}_{2}\right]_{b}
\end{gathered}
$$

If the concentration is expressed in molar fraction and the states of equilibrium are infinitesimally apart, then equation (18) can be simplified

$$
d y_{\mathrm{O}_{2}} / y_{\mathrm{O}_{2}}=d y_{\mathrm{CO}_{2}} / y_{\mathrm{CO}_{2}}
$$

where $y_{i}$ is the molar fraction of the $i$-th specie, equals to the number of mole of the specie divided by the total number of moles. Because oxygen is a product of reaction, the term on the left hand side of equation (19) is also equal to $d n_{G} / n_{G}$ based on equation (6), where $n_{G}$ is the number of moles of glucose produced. In parts per million by volume of carbon dioxide in the atmosphere, the percent change in surface greening may thus be obtained

$$
\begin{gathered}
\text { \%Greening }=100 \times d n_{G} / n_{G}= \\
100 \times d y_{\mathrm{O}_{2}} / y_{\mathrm{O}_{2}}= \\
100 \times\left(d \mathrm{ppmv}_{\mathrm{CO}_{2}} / 2\right) / \mathrm{ppmv}_{\mathrm{CO}_{2}}
\end{gathered}
$$

The division of $d \mathrm{ppmv}_{\mathrm{CO}_{2}}$ by 2 in equation 20 is required because variation in the content of carbon dioxide, $d \mathrm{ppmv}_{\mathrm{CO}_{2}}$, is provided at the end of the year. Carbon dioxide concentration, $\mathrm{ppmv}_{\mathrm{CO}_{2}}$, is the average content of carbon dioxide in the atmosphere in the period of time in consideration. 
The calculated \% Greening of the surface by equation $(20)$ does not include deforestation. To obtain Net \% Greening, the percent deforestation must be subtracted from the value calculated by equation (20).

It should be noted that changes in surface greening includes changes in the mass and size of plants and vegetation. Variation in the mass of the green matter can be calculated practically accurately for past climates by knowing variation in the content of carbon dioxide in the atmosphere. This, however, does not necessarily give variation in the area or surface cover of the green matter. A vertical growth of forests decreases the content of carbon dioxide in the atmosphere, but the incident and absorbed solar energy may remain about the same. An increase in surface cover of forests, or surface greening, on the other hand decreases the rate of solar heat to the surroundings. Therefore, by calculating energy contribution of the green matter to surface warming, deforestation can be computed for present climate change.

\section{Sample Calculations}

Publications [Petit et al., 1999, NOAA, National Oceanic and Atmospheric Administration, Earth System Research Laboratory, Global Monitoring Division, 2018, https://www.esrl.noaa.gov/gmd/cc $\mathrm{gg} /$ trends/data.html] provide records of present and past concentration of carbon dioxide in the atmosphere. These can be used to calculate trends of precipitation. For the period between 2005 and 2010 , variation in the concentration of carbon dioxide $\Delta \mathrm{ppmv}_{\mathrm{CO}_{2}}$ was 10.4. Using equation (13), variation in precipitation $\Delta \Gamma=-4.18 \times 10^{16} \mathrm{~mol}$ water, nearly $-7.53 \times 10^{14} \mathrm{~kg}$ water in five years. At surface area of $5.1 \times 10^{14} \mathrm{~m}^{2}$, annual variation in precipitation is $-0.29 \mathrm{~mm}$ annually. Using equation (16) the heat produced by carbon conversion $\Delta Q_{c}$ is $1.84 \times 10^{21} \mathrm{~J}$. The annual heat produced by the carbon cycle $d Q_{c}$ is approximately equal to $3.68 \times 10^{20} \mathrm{~J} \mathrm{yr}^{-1}$.

The observed heat gained by the surface can be calculated by knowing either sea surface temperature rise or sea level rise. The total energy gained by the surface of the earth is enthalpy that raises surface temperature and latent heat that melt ice masses. For differential displacement from equilib- rium, it can be demonstrated that they are equal. Neglecting land for it has a small thermal capacity, the total heat gained by the surface can thus be calculated by either of the following equations

$$
\begin{gathered}
d Q_{s}=2 A_{r} \times A \times d \times C p_{w} \times d T_{s} \\
d Q_{s}=2 A_{r} \times \mathrm{SLR} \times A \times L s
\end{gathered}
$$

where $A_{r}$ - area ratio between surface water and total surface area of the earth, $\approx 0.7 ; A$ - area of the surface of the earth, $\approx 5.1 \times 10^{14} \mathrm{~m}^{2}$; $d$ - depth of the mixed layer of surface water, $\approx 100 \mathrm{~m} ; C p_{w}$ - specific heat of surface water, $\approx 3.90 \times 10^{3} \mathrm{~J} \mathrm{~kg}^{-1}{ }^{\circ} \mathrm{K}^{-1} ; T_{s}$ - surface temperature, ${ }^{\circ} \mathrm{K}$; SLR - sea level rise, $\mathrm{mm} ; L_{s}$ - latent heat of ice melting, $3.34 \times 10^{5} \mathrm{~J} \mathrm{~kg}^{-1}$.

The used depth of $100 \mathrm{~m}$ for the mixed layer is based on [de Boyer Montégut et al., 2004]. University of Colorado (CU Sea Level Research Group, 2018 rel-1: Global Mean Sea Level Times Series (Seasonal Signal Removed), 2018, http://sealevel. colorado.edu/) provides sea level rise since 1993. Between 2005 and 2010, sea level rose by $14.87 \mathrm{~mm}$. Therefore, the energy gained by the surface $\Delta Q_{s}$ is $3.55 \times 10^{21} \mathrm{~J}$ based on equation $(22)$, and the annual energy gained $d Q_{s}=7.09 \times 10^{20} \mathrm{~J} \mathrm{yr}^{-1}$. From equation (14), the annual contribution of the green matter to surface warming $d Q_{g}$ is $7.09 \times 10^{20}-$ $3.68 \times 10^{20}=3.41 \times 10^{20}$ J. It can be demonstrated that the ratio $d Q_{g} / d Q_{s}$ is equal to deforestation fraction with respect to equilibrium forest inventory. This ratio is approximately equal to 0.481 of forest inventory prior to the Industrial Revolution assumed 1750. Therefore, deforestation through 2010 is nearly $48.1 \%$; this is about $0.185 \%$ of average annual deforestation. For the period of time in consideration, 2005-2010, the average content of carbon dioxide in the atmosphere is 384.74 ppmv $\mathrm{CO}_{2}$ and the average annual variation in the content of carbon dioxide is $d \mathrm{ppmv}_{\mathrm{CO}_{2}}=2.02$. Therefore, \% Greening of the surface is $0.263 \%$ annually, equation (20). The Net annual \% Greening of the surface is the difference between annual $\%$ Greening and annual \% Deforestation, approximately equal to $0.263 \%-0.185 \%=0.08 \%$.

Following the last Glacial Maximum during the period of time 18,470-13,800 Before Present (BP), surface temperature increased by $6^{\circ} \mathrm{K}$. Using equation (21), the surface thus gained $1.67 \times 10^{24} \mathrm{~J}$ during that period of time. 
The world energy production can be estimated since 1990 based on energy consumption records complied by [EIA, 2016]. Energy is reported in British Thermal Units, which should be converted to Joules for comparison with the calculations. For example, Figure 1-2, page 8, of [EIA, 2016] reveals that OECD countries consumed in 2011 nearly 240 quadrillion BTU. Non-OECD countries consumed approximately 310 quadrillion BTU in that year. The world energy production for 2011 is thus equal to $(240+310) \mathrm{BTU} \times 1055.06 \mathrm{~J} \mathrm{BTU}^{-1} \times$ $10^{15}$ Quadrillion $^{-1}=5.80 \times 10^{20} \mathrm{~J}$.

\section{Discussion}

The thermodynamic processes of the carbon cycles presented in this work will be discussed for compliance with the laws of thermodynamics. Equation (4) is a spontaneous reaction and does not require external source of energy. Light is required for the photosynthesis reaction of equation (6), which is available in sunrays. Evaporation and condensation of water vapor on the other hand, equation (5), merit discussion. During cooling cycles, when the concentration of carbon dioxide in the atmosphere decreases with time, water vapor content in the atmosphere decreases based on equation (9). This prompts more surface evaporation and surface cooling. Surface water evaporation is a spontaneous process for the surface is a heat reservoir and its temperature is greater than the temperature of the atmosphere. When, however, the content of carbon dioxide increases such as the present time or past interglacial periods, water va- por has to condense on the surface, and surface temperature increases. This process is equivalent to heat transfer from the cold atmosphere to the warmer surface, which is a non-spontaneous process and requires external mechanical work. It is available, and the atmosphere provides such a work in the form of potential energy. Presently, the height of the atmosphere is decreasing, and this decrease in potential energy of the atmosphere provides the required work. [Thompson and Solomon, 2002 observed reduction in geopotential heights of the upper atmosphere. The decreasing trends examined at the South Pole were assumed to be attributed to ozone layer depletion. However, greenhouse gas emissions are not excluded as a cause. For lack of data relative to trends of geopotential heights, the observed reduction at the South Pole could be typical elsewhere. Therefore, all of the thermodynamic processes of the carbon cycle discussed are feasible from a thermodynamic prospective.

Table 1 and Table 2 summarize carbon cycle parameters for selected periods of times where past climate transformations may be assumed linear with time. The period 18,470-13,800 Before Present (BP) followed the last Glacial Maximum, characterized by severe cold and dry climate [ Van der Hammen, 1974. Cold surface temperature, reduced carbon dioxide content in the atmosphere, glaciers cover of land, and decreased of water availability; all are unfavorable for life. Widespread biological decay, reduced photosynthesis, and significant increase in solar energy available to the surroundings occurred. These increased surface temperature and carbon dioxide content in the atmo-

Table 1. Summary of Past Climates Energy

\begin{tabular}{|c|c|c|c|}
\hline Line & $\begin{array}{l}\text { Period } \\
\text { Description }\end{array}$ & $\begin{array}{l}18,470-13,800 \\
(\mathrm{BP})\end{array}$ & $\begin{array}{c}112,320-106,500 \\
(\mathrm{BP})\end{array}$ \\
\hline 1 & Climate transformation duration, years & 4670 & 5820 \\
\hline 2 & Surface temperature change, ${ }^{\circ} \mathrm{C}$ & 6.00 & -4.50 \\
\hline 3 & Variation in carbon dioxide, ppmv & 57.00 & -35.00 \\
\hline 4 & Annual precipitation trend, $\mathrm{mm}$ & -0.002 & 0.001 \\
\hline 5 & Average annual energy exchanged with the surface, $d Q_{s}, \mathrm{~J}$ & $3.58 \mathrm{E} 20$ & $-2.15 \mathrm{E} 20$ \\
\hline 6 & Average annual heat produced by the carbon cycle, $d Q_{c}, \mathrm{~J}$ & $2.02 \mathrm{E} 21$ & $-1.02 \mathrm{E} 21$ \\
\hline 7 & $\begin{array}{l}\text { Average annual heat added to the surface by } \\
\text { the green matter, } d Q_{g}, \mathrm{~J}\end{array}$ & $-1.66 \mathrm{E} 21$ & $1.02 \mathrm{E} 21$ \\
\hline
\end{tabular}


Table 2. Past Climate Parameters

\begin{tabular}{llcc}
\hline Line & $\begin{array}{l}\text { Period } \\
\text { Description }\end{array}$ & $\begin{array}{c}18,470-13,800 \\
(\mathrm{BP})\end{array}$ & $\begin{array}{c}112,320-106,500 \\
(\mathrm{BP})\end{array}$ \\
\hline 1 & Climate transformation duration, years & 4670 & 5820 \\
2 & Average concentration of carbon dioxide, ppmv & 235.00 & 250.00 \\
3 & Average annual change in carbon dioxide, ppmv & 0.012 & -0.006 \\
4 & Annual \% Greening of the surface & 0.003 & -0.001 \\
5 & Annual \% Deforestation of the surface & 0.000 & 0.000 \\
6 & Net annual \% Greening of the surface & 0.003 & -0.001 \\
\hline
\end{tabular}

sphere. Line 7 of Table 1 reveals a negative heat contribution of the green matter to surface warming, thus suggesting an increase in surface greening by approximately $0.003 \%$ annually, Table 2 . The total contribution of this warming campaign to surface greening was nearly $12 \%$ in approximately $4.7 \times 10^{3}$ years. This was typical for all past interglacial periods.

Conversely, the cooling period of time between 112,320-106,500 BP reveals contraction in the size of the green matter, line 7 of Table 1. Plants contributed heat to surface warming and simultaneously their mass increased. This is evident from the decreases in the content of carbon dioxide in the atmosphere, line 3 of Table 1. Apparently, during severe cooling periods, the green matter increases in density and vertical growth, not necessarily in size or surface cover. This is in contrast with warming periods where the growth appears to be predominately horizontal and sporadic.

The natural carbon cycle has been disabled since farming was invented, and deforestation has become a parameter of the cycle. In Table 3 and Table 4, climate parameters of the present carbon cycle are tabulated. A comparison between lines 6 and 8 of Table 3 reveals that present annual contribution of deforestation to surface warming is nearly $50 \%$. Assuming major deforestations began around the Industrial Revolution, 1750, it can be concluded that deforestation trend is $0.19 \%$ annually. This is in good agreement with $[F A O, 2016 \mathrm{a}$, $2016 \mathrm{~b}, 2000$ estimate on the ground of $0.1 \%$ to $0.25 \%$. As line 9 of Table 3 shows, the heat added by the green matter has a decreasing trend, and deforestation is thus decreasing. The calculated Net annual percent Greening of the surface is $0.08 \%$, line 6 of Table 4. [FAO, 2016a records reveals surface greening of $0.03 \%$ annually and [Zaichun Zhu et al., 2016 observed annual surface greening of $0.44 \%$. The calculated Net annual percent Greening falls well within the observed range.

Also, industrialization and fossil fuel burning have become integral part of the thermodynamics of the carbon cycle for they produce heat and carbon dioxide. Presently, carbon dioxide trend in the atmosphere is considerably greater than in past climates, line 3 of Table 2 and Table 4 . The calculated present precipitation trend is $-0.31 \mathrm{~mm}$ annually, nearly 150 times greater than past climates, line 4 of Table 1 and Table 3. [Philandras et al., 2011 observed -0.3 to $-0.7 \mathrm{~mm}$ annual precipitation trend and [Longobardi and Villani, 2009] observed $-0.6 \mathrm{~mm}$ annually. The calculated trend falls within the observed range. A comparison between lines 5 and 7 of Table 3 reveals that only $65 \%$ of the present energy produced by the world remains in the climate, a decrease from $83 \%$ for the period of time 1993-1998. Approximate annual decrease in the contribution of energy production to surface warming is nearly $-0.82 \%$ annually. The decrease may be attributed to using energy sources that produce less net molecules of carbon dioxide than carbon. This is in line with the present practice of using renewables, biomass, nuclear, and methane as sources of energy.

The observed glacier melting and disappearance can only be explained by latent heat transfer of water vapor condensation onto the surface, which support this work. Heat transfer with phase change of water vapor can provide sufficient heat transfer coefficient to melt glaciers at the observed ambient temperature rise of $0.01^{\circ} \mathrm{K}$ annually. Other heat 
Table 3. Summary of Present Climate Energy

\begin{tabular}{|c|c|c|c|c|c|}
\hline Line & $\begin{array}{l}\text { Period } \\
\text { Description }\end{array}$ & 1993-1998 & $2000-2005$ & $2005-2010$ & $2010-015$ \\
\hline 1 & Climate transformation duration, years & 5 & 5 & 5 & 5 \\
\hline 2 & Sea level rise, $\mathrm{mm}$ & 15.83 & 16.63 & 14.87 & 16.63 \\
\hline 3 & Variation in carbon dioxide, ppmv & 9.60 & 10.25 & 10.40 & 10.93 \\
\hline 4 & Annual precipitation trend, mm & -0.27 & -0.29 & -0.29 & -0.31 \\
\hline 5 & Average annual energy produced by the world, $\mathrm{J}$ & 4.10E20 & $4.91 \mathrm{E} 20$ & $5.41 \mathrm{E} 20$ & $5.92 \mathrm{E} 20$ \\
\hline 6 & $\begin{array}{l}\text { Average annual energy exchanged with the } \\
\text { surface, } d Q_{s}, \mathrm{~J}\end{array}$ & $7.55 \mathrm{E} 20$ & 7.93E20 & 7.09E20 & 7.93E20 \\
\hline 7 & $\begin{array}{l}\text { Average annual heat produced by the } \\
\text { carbon cycle, } d Q_{c}, \mathrm{~J}\end{array}$ & $3.40 \mathrm{E} 20$ & $3.63 \mathrm{E} 20$ & $3.68 \mathrm{E} 20$ & $3.87 \mathrm{E} 20$ \\
\hline 8 & $\begin{array}{l}\text { Average annual heat added by the } \\
\text { green matter, } d Q_{g}, \mathrm{~J}\end{array}$ & $4.15 \mathrm{E} 20$ & $4.30 \mathrm{E} 20$ & $3.41 \mathrm{E} 20$ & $4.06 \mathrm{E} 20$ \\
\hline 9 & $\begin{array}{l}\text { Annual trend of the heat added to the surface by } \\
\text { the green matter, } \mathrm{J}\end{array}$ & \multicolumn{4}{|c|}{$-3.00 \mathrm{E} 19$} \\
\hline
\end{tabular}

transfer phenomena cannot explain this melting based on practical engineering applications [Perry and Green, 1984]. [Berezovskaya et al., 2004 supports this conclusion as well. This publication reveals a decrease in precipitation in the large Siberian watersheds (Ob, Yenisei, and Lena rivers), yet river runoffs increased. Only by water vapor condensation can this observation be explained. A decrease in precipitation by $1.0 \mathrm{~mm}$ produces one kilogram of water vapor per square meter annually based on this work. When condensed on permafrost, about $8.4 \mathrm{~mm}$ of total melt is produced. Therefore, river runoffs increased even though precipitation decreased with time.

The calculations reveal that most of anthropogenic heat production has contributed to sur- face warming. Because the world is unevenly populated, surface warming varies at the hemispheric and regional levels, which is observed [IPCC,2013. The majority of the world population is in the northern hemisphere, and this hemisphere is thus expected to warm more than the southern hemisphere.

As discussed in the background section, climate models do not appear to provide calculated values of deforestation and surface greening. Therefore, comparison of most of the computed and relevant climate parameters for the objectives of this work with climate models cannot be made at this time. The report, $[I P C C, 2013$, reveals that between January 2001 and December 2012 the earth has been steadily accumulating energy at the rate

Table 4. Present Climate Parameters

Line Period

1993-1998 2000-2005 2005-2010 2010-2015

Description

\begin{tabular}{llcccc}
1 & Climate transformation duration, years & 5 & 5 & 5 & 5 \\
2 & Average concentration of carbon dioxide, ppmv & 361.63 & 374.52 & 384.74 & 395.23 \\
3 & Average annual change in carbon dioxide, ppmv & 1.920 & 2.050 & 2.020 & 2.190 \\
4 & Annual \% Greening of the surface & 0.265 & 0.274 & 0.263 & 0.277 \\
5 & Annual \% Deforestation of the surface & 0.224 & 0.215 & 0.187 & 0.195 \\
6 & Net annual \% Greening of the surface & 0.041 & 0.059 & 0.076 & 0.081 \\
\hline
\end{tabular}


of $0.5 \pm 0.43 \mathrm{~W} \mathrm{~m}^{-2}$, Chapter 2, Section 2.3.2. The calculated energy added to the surface during that period of time is nearly $8.30 \times 10^{21} \mathrm{~J}$, line 6 of Table 3. In Radiative Forcing terms, $\mathrm{Wm}^{-2}$, the calculated value of accumulated energy by climate models is practically equal to that calculated in this work.

\section{Conclusions}

The discussion section reveals agreements between calculations and basics of thermodynamics and observations. It is thus reasonable to conclude that the interactions between the carbon cycle and biosphere subsystems may be calculated using traditional thermodynamic equations. The heat produced by the carbon cycle warms the surface of the earth, and the heat removed by the carbon cycle cools the surface. The procedure presented is not limited to computing observed changes in climate parameters but also their projected values into the future. If carbon dioxide emission and deforestation projection scenarios are given, equation (16) and equation $(20)$ can be used to calculate $\Delta Q_{c}$ and \% Greening practically accurately. Precipitation trend can be computed by equation (13). Equation (14) can then be applied to calculate the heat added to the surface, $d Q_{s}$, and sea level and sea surface temperature rise obtained by equations (21) and (22).

Clearly, understanding the carbon cycle and its thermodynamic interactions with human activities and other biosphere subsystems is important because the environment is impacted by these interactions. Uneven distribution of surface warming at the hemispheric and regional levels must alter global and regional hydrology. This includes but not limited to trends of precipitation, open water evaporation, and frequency of intense precipitation. Basis of engineering design will, therefore, vary particularly for civil, agriculture, and environment related projects. For instance, projecting evaporation and precipitation trends in a warming world are critical for projects such as dams, retention lagoons, zero discharge ponds, irrigation, and others. Similarly, sea level rise can have considerable impact on the feasibility of projects located in the proximity of surface water. Surface deforestation and greening are important for sustainable forest management. This work may be used to assess the general state of world forests without requiring forest inventories on the ground, and may assist in projecting basis of engineering design.

Acknowledgments. My sincere thanks to the team of Russian Journal of Earth Sciences for their review and comments. Mrs. Olga Aleksanova and Mr. Stanislav Nekhoroshev are gratefully acknowledged for handling this manuscript. The time and effort of those who contributed to this work directly or indirectly are appreciated.

\section{References}

Berezovskaya, S., $\quad$ D. Yang, $\quad$ D. L. Kane (2004), Compatibility analysis of precipitation and runoff trends over the large Siberian watersheds, Geophysical Research Letters, 31, L21502, Crossref

de Boyer Montégut, C., G. Madec, S. A. Fischer, A. Lazar, D. Iudicone (2004), Mixed layer depth over the global ocean: An examination of profile data and profile-base climatology, J. Geophys. Res., 109, C12003, Crossref

EIA (2016), International Energy Outlook 2016 with Projections to 20140, 7-8 pp. United states Energy Information administration. U.S. Department of Energy, Washington DD, USA.

FAO (2016a), Global Forest Resources Assessment 2015, How the World Forests Changing. Second Edition, 16-31 pp. Food and Agriculture Organization of the United Nations, Rome, Italy. (http://www.fao.org/3/a-i4793e.pdf)

FAO (2016b), State of the World's Forests. Forests and Agriculture: Land-use challenges and opportunities, 11-16 pp. Food and Agriculture Organization of the United Nations, Rome, Italy. (http://www.fao.org/publications/sofo/2016/en/)

FAO (2000), Global Forest Resources Assessment 2000 Main Report, Chapter 2 Wood volume and woody biomass, Changes 1990-2000, Food and Agriculture Organization of the United Nations, Rome, Italy. (http://www.fao.org/docrep/004/y1997e/y19 97e00.htm)

Fleagle, R. G., J. A. Businger (1980), An Introduction to Atmospheric Physics, 2nd edn. (J. Van Mieghem and A. L. Hales (eds.), 79-80, 415 pp. Academic Press, New York, USA.

IPCC (2013), Intergovernmental Panel On Climate Change, IPCC Fifth Assessment Report (AR5) Climate Change, The Physical Science Basis, Cambridge 
University Press, Cambridge, Great Britain.

Longobardi, A., P. Villani (2009), Trend analysis of annual and seasonal rainfall time series in the Mediterranean area, Int. J. Climatol., Crossref

Perry, R. H., D. Green (1984), Perry's Chemical Engineers Handbook, 6th ed., Crawford, H. B., B. E. Eckes (eds.), 4-169 pp. Mc Graw-Hill, New York, USA.

Petit, et al. (1999), Climate and atmospheric history of the past 420,000 years from the Vostok ice core, Antarctica, Nature, 399, 429-436, Crossref

Philandras, C. M., P. T. Nastos, J. Kapsomenakis, K. C. Douvis, G. Tselioudis, C. S. Zerefos (2011), Long term precipitation trends and variability within the Mediterranean region, Nat. Hazards Earth Syst. Sci., 11, 3235-3250, Crossref
Thompson, D. W. J., S. Solomon (2002), Interpretation of Recent Southern Hemisphere Climate Chang, Science, 296, 895-899, Crossref

Van der Hammen, T. (1974), The Pleistocene Changes of Vegetation and Climate in Tropical South America, Journal of Biogeography, 1, No. 1, 3-26, Crossref

Zaichun, Zhu, et al. (2016), Greening of the Earth and its drivers, Nature Climate Change, 6, 791-795, Crossref

\section{Corresponding author:}

Nabil H. Swedan, 1524 Mission Road, Apt. 9 Kodiak, Alaska, 99615, USA. Telephone: (650) 8883123 (nabilswedan2@gmail.com; swedan@pacificengineeringpllc. com) 